\title{
ANALISIS STABILITAS BACK-TO-BACK MECHANICALLY STABILIZED EARTH WALLS (STUDI KASUS JALAN LAYANG DI SULAWESI SELATAN)
}

\author{
Yordan Salim ${ }^{1}$ dan Andryan Suhendra ${ }^{2}$ \\ ${ }^{1}$ Program Studi Sarjana Teknik Sipil, Universitas Tarumanagara, Jl. Letjen S. Parman No.1 Jakarta \\ yordan.325170080@stu.untar.ac.id \\ ${ }^{2}$ Program Studi Sarjana Teknik Sipil, Universitas Tarumanagara, Jl. Letjen S. Parman No.1 Jakarta \\ andryansuhendra@yahoo.com
}

Masuk: 12-07-2021, revisi: 06-08-2021, diterima untuk diterbitkan: 19-08-2021

\begin{abstract}
In urban areas, the requirement for roads is always increasing. This has resulted in various problems such as limited land so that it needs to construct a proper retaining wall. The type of retaining wall that will be discussed is backto-back mechanically stabilized earth walls. The author analyzes the minimum reinforcement length required for the stability of the retaining wall structure. The author also analyzes the use of backfill material from back-to-back mechanically stabilized earth walls. In this study, two types of backfill materials were used, sand and laterite. The author analyzes the stability of the structure using manual calculations and with software based on finite element methods with several differences in the reinforcement length of the geogrid. In manual analysis obtained the tensile force that occurs in the geogrid and the safety factor for the external stability. In the analysis using the software obtained the safety factor and deformation that occurs in the structure. The results of this study are the minimum ratio of reinforcement length to height, that is $L=0.66 \mathrm{H}$ for sand and $\mathrm{L}=0.6 \mathrm{H}$ for laterite. The requirement of geogrid tensile capacity for laterite is smaller than for sand.
\end{abstract}

Keywords: reinforcement length, mechanically stabilized earth walls, geogrid, safety factor

\begin{abstract}
ABSTRAK
Pada daerah perkotaan, kebutuhan akan jalan selalu meningkat. Hal ini mengakibatkan berbagai masalah seperti keterbatasan lahan sehingga perlu konstruksi dinding penahan tanah yang tepat. Jenis dinding penahan tanah yang akan dibahas adalah back-to-back mechanically stabilized earth walls. Penulis menganalisis panjang penjangkaran minimum yang diperlukan untuk statbilitas struktur dinding penahan tanah. Penulis juga menganalisis penggunaan material timbunan dari back-to-back mechanically stabilized earth walls. Pada penelitian ini digunakan dua jenis material timbunan yaitu pasir dan tanah merah. Penulis menganalis kestabilan dari struktur menggunakan perhitungan manual dan dengan software berbasis metode elemen hingga dengan beberapa variasi panjang penjangkaran dari geogrid. Pada analisis manual, diperoleh gaya tarik yang terjadi pada geogrid dan faktor keamanan dari stabilitas eksternal struktur. Pada analisis menggunakan program diperoleh faktor keamanan dan deformasi yang terjadi pada struktur. Adapun hasil dari penelitian ini yaitu rasio panjang penjangkaran terhadap tinggi minimum yaitu $\mathrm{L}=0,66 \mathrm{H}$ pada pasir dan $\mathrm{L}=0,6 \mathrm{H}$ untuk tanah merah. Kebutuhan kapasitas tarik geogrid untuk tanah merah lebih kecil daripada pasir.
\end{abstract}

Kata kunci: panjang penjangkaran, mechanically stabilized earh walls, geogrid, faktor keamanan

\section{PENDAHULUAN}

Jalan merupakan infrastruktur yang sangat penting untuk mobilitas manusia dan barang. Kontur tanah di Indonesia cukup bergelombang sehingga banyak jalan di Indonesia dibangun berlikuk serta menanjak dan menurun. Pada daerah dengan perbedaan ketinggian yang ekstrem, perlu dibangunnya jembatan agar jarak tempuh lebih pendek serta kontur jalan tidak ekstrem sehingga nyaman saat dilalui.

Pada daerah perkotaaan, kebutuhan jalan meningkat seiring meningkatnya jumlah kendaraan. Karena meningkatnya pembangunan jalan, maka muncul masalah baru yaitu keterbatasan lahan. Untuk mengatasi permasalahan tersebut maka dibangun flyover dan underpass. Untuk konstruksi flyover dan underpass terdapat bagian yang penting yaitu dinding penahan tanah (DPT). 
Dinding penahan tanah adalah suatu konstruksi yang mempunyai fungsi untuk menahan gaya tekanan aktif lateral dari tanah maupun air. Konstruksi dinding penahan tanah harus direncanakan agar mampu menahan gaya berupa momen guling, gaya berat sendiri, gaya lateral aktif-pasif tanah/air, gaya gelincir (sliding) dan gaya angkat (uplift). (Khuzaifah, 2019)

Untuk mengatasi masalah keterbatasan lahan, salah satu jenis dinding penahan tanah yang dapat digunakan adalah dinding Mechanically Stabilized Earth (MSE). Menurut Ratag, Mandagi, \& Legrans (2018), dinding MSE dengan penutup muka beton pracetak pada umumnya akan lebih murah jika dibandingkan dengan dinding penahan beton yang diperkuat untuk ketinggian lebih dari 3 m pada kondisi fondasi yang baik. Pada umumnya, dinding MSE lebih murah dan mudah dikerjakan dibandingkan dengan struktur penahan tanah dengan beton lainnya, terutama pada tanah fondasi yang kurang baik.

Identifikasi masalah dalam penelitian ini adalah panjang penjangkaran perkuatan yang paling optimal berdasarkan parameter tanah yang ada.

Berikut batasan masalah dalam penelitian ini.

1. Lokasi penelitian di Sulawesi Selatan.

2. Tidak memperhitungkan biaya (cost).

3. Tidak merencanakan drainase.

4. Menggunakan program berbasis elemen hingga.

5. Menggunakan perkuatan geogrid tipe PET dengan coating PVC.

6. Tidak memperhitungkan penurunan konsolidasi.

7. Tidak memperhitungkan pengaruh creep pada tanah merah.

8. Analisis yang dilakukan untuk jangka pendek.

Berikut rumusan masalah dalam penelitian ini.

1. Bagaimana pengaruh dari panjang penjangkaran pada back-to-back mechanically stabilized earth walls terhadap stabilitas struktur?

2. Bagaimana perbandingan rasio penjangkaran terhadap tinggi back-to-back mechanically stabilized earth walls?

3. Bagaimana pengaruh penggunaan tanah merah dan pasir sebagai bahan backfill dari back-to-back mechanically stabilized earth walls?

Berikut tujuan dari penelitian ini.

1. Mengetahui pengaruh dari panjang penjangkaran pada back-to-back mechanically stabilized earth walls terhadap stabilitas struktur.

2. Mengetahui perbandingan rasio penjangkaran terhadap tinggi back-to-back mechanically stabilized earth walls.

3. Mengetahui pengaruh penggunaan tanah merah dan pasir sebagai bahan backfill dari back-to-back mechanically stabilized earth walls.

\section{Back-to-back mechanically stabilized walls}

Back-to-back Mechanically Stabilized Earth (BBMSE) Walls sering digunakan untuk ramps jalan raya. Untuk dinding yang dibangun saling membelakangi ditunjukkan pada di bawah ini, nilai tekanan lateral yang dimodifikasi mempengaruhi perhitungan stabilitas eksternal. Terdapat dua kasus seperti gambar di bawah ini.
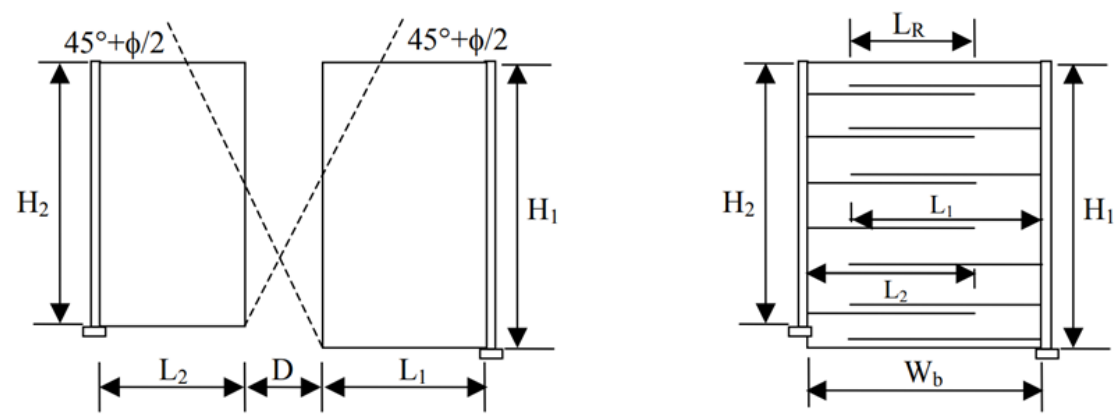

Gambar 1. Back-to-back mechanically stabilized earth walls (FHWA, 2009) 
Kasus I

Untuk Kasus I, lebar dinding keseluruhan cukup besar sehingga setiap dinding dapat didesain secara tersendiri. Pada kondisi ini, tidak ada perkuatan yang overlapping. Secara teoritis, jika jarak, D, antara dua dinding lebih pendek dari $\mathrm{D}=\mathrm{H}_{1} \tan \left(45^{\circ}-\phi^{\circ} / 2\right)$ dimana $\mathrm{H}_{1}$ ketinggian dinding yang lebih tinggi, maka tekanan aktif di belakang setiap dinding tidak dapat sepenuhnya menyebar dan daya dorong aktif berkurang.

Kasus II

Untuk Kasus II, terjadi overlapping perkuatan sehingga kedua dinding saling berinteraksi. Ketika overlapping (L ${ }_{\mathrm{R}}$ ) lebih besar dari $0,3 \mathrm{H}_{2}$, di mana $\mathrm{H}_{2}$ ketinggian dinding yang lebih pendek maka tidak ada tekanan aktif tanah atau dalam kata lain, analisis stabilitas eksternal tidak perlu diperhitungkan. Antara Kasus I dan Kasus II, tekanan tanahh aktif dapat berbentuk interpolasi linier dari kasus aktif penuh menjadi nol. Interpolasi dimulai dari $\mathrm{D}=\mathrm{H}_{1} \tan \left(45^{\circ}\right.$ $\phi^{\circ} / 2$ ) hingga $\mathrm{LR}=0,3 \mathrm{H} 2$.

Untuk geometri Kasus II dengan overlap $\left(\mathrm{L}_{\mathrm{R}}\right)$ lebih besar dari 0,3 $\mathrm{H}_{2}$, pedoman berikut digunakan:

- $\quad$ L1/H1 $\geq 0.6$ dimana L1 dan H1 masing-masing adalah panjang perkuatan dan tinggi dari tembok yang lebih tinggi.

- L2/H2 $\geq 0.6$ dimana L2 dan H2 adalah panjang perkuatan dan tinggi masing-masing dinding yang lebih pendek.

- $\mathrm{Wb} / \mathrm{H} 1 \geq 1.1$ dimana $\mathrm{Wb}$ adalah lebar dasar seperti yang ditunjukkan pada Gambar 2.48 dan $\mathrm{H} 1$ adalah tinggi alas tembok yang lebih tinggi.

\section{Perencanaan dinding MSE}

Menurut Ratag, Mandagi, \& Legrans (2018), perencanaan dinding MSE terdiri dari beberapa bagian yang didesain dan dianalisis yaitu:

1. Umur rencana

Perencanan untuk umur rencana dari suatu MSEW berdasarkan pertimbangan pengaruh jangka panjang terhadap potensi kerusakan dari material, rembesan dan pengaruh lingkungan terhadap komponen MSEW. Umur rencana minimum untuk dinding penahan tanah permanen adalah 75 tahun, sedangkan dinding penahan sementara dapat didesain dengan umur rencana 36 bulan atau kurang. Umur rencana struktur yang memiliki fungsi vital dapat digunakan 100 tahun. (FHWA, 2009)

\section{Facing panel}

Panel muka merupakan bagian dari struktur depan MSEW yang dibuat dari beton pra-cetak, yang saling terkunci dan menyatu. Antara panel yang satu dengan yang lain disatukan dengan dowels bars sehingga bersifat fleksibel dan dapat menoleransi perbedaan penurunan (differential settlement). Panel muka sangat penting dalam hal estetika karena hanya bagian ini yang satu-satunya terlihat dari luar setelah konstruksi selesai. Dalam hal konstruksi dapat berfungsi sebagai saluran drainase. Tebal minimum panel beton adalah $140 \mathrm{~mm}$ (5,5 inci) dan dapat berbentuk persegi, segitiga, bujur sangkar, heksagonal dan lain-lain. Dimensi panel beton adalah tinggi 1,5 m (5 kaki) dengan lebar 1,5 - 3 m (5 - 10 kaki). (FHWA, 2009)

\section{Dimensi levelling pad}

Levelling pad umumnya terbuat dari beton (umumnya 2500 psi atau 17,2 Mpa). Mutu beton dan ketebalan harus dapat menahan beban sehingga mengejinkan terjadinya retak saat terjadi penurunan setempat untuk meredam konsentrasi tegangan yang terjadi. Ketebalan levelling pad umumnya 6 inci (150 mm), sedangkan lebarnya harus lebih besar minimum 3 inci (150 mm) maka lebar levelling pad adalah 12 inch (300 mm). Toleransi untuk kerataan levelling pad adalah 1/8 inci (3 mm) untuk setiap 10 kaki (3 m). (FHWA, 2009)

\section{Kedalaman penanaman struktur}

Kaki struktur harus ditanam di bawah permukaan tanah agar tidak terjadi kegagalan lokal. Pada kondisi tanah dasar yang baik, maka minimum penanaman (embedment) adalah $\mathrm{H} / 20$ untuk dinding dan $\mathrm{H} / 10$ untuk pangkal jembatan dan tidak boleh kurang dari 2 kaki (0,6 m). Untuk kondisi tanah dasar lunak diperlukan fondasi yang baik dan kuat. (FHWA, 2009)

\section{Panjang penjangkaran}

Panjang penjangkaran minimum adalah 0,7 tinggi struktur atau minimal $3 \mathrm{~m}$. Yang dimaksud tinggi struktur adalah tinggi dari levelling pad sampai ke atas struktur.

\section{Drainase}

Stabilitas struktur timbunan dengan perkuatan tergantung pada baik tidaknya sistem drainase. Peningkatan tegangan pori pada timbunan dengan perkuatan akan mengurangi tekanan overburden pada tingkat perkuatan, sehingga dapat mengurangi kapasitas cabut dan tahanan terhadap geser lateral. Ada dua tipe drainase yaitu internal dan eksternal. 
Drainase internal untuk drainase aliran air permukaan yang meresap ke dalam struktur dinding penahan tanah maupun aliran air tanah pada belakang struktur dinding. Drainase internal harus disesuaikan dengan karakteristik tanah timbunan yang digunakan. Drainase eksternal untuk drainase aliran permukaan air yang dapat menyebabkan erosi. Drainase eksternal harus disesuaikan dengan lokasi struktur dan faktor hidrogeologi.

\section{Stabilitas internal}

Kegagalan internal dinding MSE dapat terjadi dalam dua moda kegagalan yang berbeda, tetapi keduanya menyebabkan pergerakan yang besar pada struktur dinding MSE, hingga terjadinya keruntuhan pada struktur dinding. Kedua moda kegagalan internal tersebut adalah sebagai berikut:

a) kegagalan pada material perkuatan, yaitu perpanjangan yang berlebihan atau putusnya perkuatan, karena tingginya gaya tarik pada perkuatan;

b) kegagalan karena tercabutnya perkuatan dari massa tanah timbunan karena tingginya gaya tarik pada perkuatan.

Analisis stabilitas internal dari dinding MSE dapat dihitung seperti di bawah ini:

1. Kapasitas tarik

Kapasitas tarik maksimum dari geogrid harus direduksi dengan membagi kapasitas ultimit dengan faktor reduksi.

Kapasitas tarik ijin $\mathrm{T}_{\mathrm{al}}$ dapat diperoleh dari persamaan:

$$
T_{a l}=\frac{T_{u l t}}{R F_{I D \times R F_{C R} \times R F_{D}}}
$$

dengan $\mathrm{T}_{\mathrm{ult}}=$ kapasitas tarik maksimum geogrid, $\mathrm{RF}_{\mathrm{ID}}=$ faktor reduksi kerusakan akibat instalasi, $\mathrm{RF}_{\mathrm{CR}}=$ faktor reduksi akibat creep dan $\mathrm{RF}_{\mathrm{D}}=$ faktor reduksi kekuatan.

2. Kapasitas cabut

Kapasitas cabut $\mathrm{P}_{\mathrm{r}}$ dapat diperoleh dari persamaan:

$$
P_{r}=\emptyset \cdot L_{e} F^{*} \cdot \alpha \cdot \sigma_{v} \cdot C \cdot R_{c}
$$

dengan $\varnothing=$ faktor reduksi, $L_{e}=$ panjang penjangkaran, $F^{*}=$ faktor kapasitas cabut, $\alpha=$ faktor koreksi, $\sigma_{\mathrm{v}}=$ tegangan tanah efektif vertikal, $\mathrm{C}=$ perimeter efektif perkuatan dan $\mathrm{R}_{\mathrm{c}}=$ rasio perbandingan material.

3. Gaya tarik maksimum yang terjadi

Besarnya gaya yang terjadi pada perkuatan dipengaruhi oleh tegangan lateral tanah timbunan.

Gaya tarik maksimum saat kondisi statik $\mathrm{T}_{\max }$ dapat diperoleh dari persamaan:

$$
T_{\max }=\frac{\sigma_{H} S_{V}}{R_{C}}
$$

Dengan $\sigma_{\mathrm{H}}=$ tegangan tanah efektif lateral dan $\mathrm{S}_{\mathrm{V}}=$ spasi vertikal perkuatan.

Gaya tarik maksimum saat kondisi seismik $\mathrm{T}_{\mathrm{md}}$ dapat diperoleh dari persamaan:

$$
T_{m d}=\frac{K_{a v} W_{a}}{n}
$$

Dengan $\mathrm{k}_{\mathrm{av}}=$ percepatan tanah maksimum, $\mathrm{W}_{\mathrm{a}}=$ massa tanah pada resisting zone dan $\mathrm{n}=$ jumlah lapisan perkuatan .

Gaya tarik total yang terjadi pada geogrid dapat dihitung dengan menjumlahkan gaya tarik pada kondisi statik deangan gaya tarik pada kondisi seismik.

\section{Stabilitas eksternal}

Stabilitas eksternal pada dinding MSE terdiri dari stabilitas guling, stabilitas geser, dan daya dukung pondasi. Pada perhitungan ini gaya yang bekerja berupa tekanan lateral tanah timbunan di belakang dinding. Untuk tanah yang memiliki kohesi, tekanan tanah lateral direduksi oleh kohesinya. Analisis stabilitas eksternal dari MSE secara umum dapat dihitung sebagai berikut:

1. Stabilitas geser

Stabilitas geser yaitu perbandingan gaya yang menahan dengan gaya-gaya yang mendorong. Dengan perbandingan gaya penahan dan pendorong, akan didapat suatu faktor keamanan stabilitas geser.

Faktor keamanan geser $\mathrm{FK}_{\text {geser }}$ dapat diperoleh dari persamaan: 


$$
F K_{\text {geser }}=\frac{R v \cdot \tan \delta+F_{3}}{F_{1}+F_{2}}
$$

Dengan $\mathrm{R}_{\mathrm{v}}=$ resultan gaya vertikal, $\mathrm{F}_{1}=$ tegangan lateral aktif akibat beban luar, $\mathrm{F}_{2}=$ tegangan lateral aktif tanah dan $\mathrm{F}_{3}=$ tegangan lateral pasif tanah.

2. Stabilitas guling

Momen yang menyebabkan terjadinya guling adalah gaya dorongan aktif tanah dan beban terhadap titik pusat guling. sedangkan gaya yang menahan guling adalah gaya beban sendiri tanah dan gaya pasif bagian depan tanah terhadap titik pusat guling.

Faktor keamanan guling FKguling dapat diperoleh dari persamaan:

$$
F K_{\text {guling }}=\frac{R_{v} \cdot \frac{L}{2}+F_{3} \cdot \frac{d}{3}}{F_{1} \cdot \frac{H}{2}+F_{2} \cdot \frac{H}{3}}
$$

Dengan $\mathrm{L}=$ panjang penjangkaran, $\mathrm{H}=$ tinggi dinding dan $\mathrm{d}=$ kedalaman penanaman (embedment)

3. Gaya seismik

Untuk stabilitas eksternal dinding MSE dalam kondisi seismik, terdapat tambahan gaya yang bekerja tanah dibelakang struktur berupa gaya dorong horizontal yang dinamis $\left(\mathrm{P}_{\mathrm{AE}}\right)$ dan gaya inersia horizontal $\mathrm{P}_{\mathrm{IR}}=\mathrm{M} \cdot \alpha_{\mathrm{m}}$, dimana $\mathrm{M}$ adalah massa tanah dan $\alpha_{\mathrm{m}}$ adalah percepatan tanah puncak.

Percepatan tanah puncak $\alpha_{\mathrm{m}}$ dapat diperoleh dari persamaan:

$$
\alpha_{m}=\alpha \cdot K_{\max }
$$

Dengan $\alpha=$ faktor koreksi dan $\mathrm{K}_{\max }=$ percepatan tanah $\left(\mathrm{K}_{\max }=\right.$ PGA.F $\left.\mathrm{F}_{\mathrm{pga}}\right)$.

Koefisien tekanan aktif tanah seismik $\mathrm{K}_{\mathrm{AE}}$ dapat diperoleh dari persamaan:

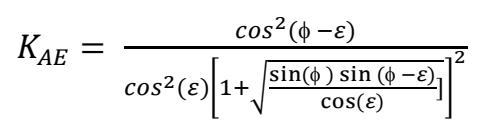

Dengan $\phi=$ sudut geser tanah dan $\varepsilon=\tan ^{-1}\left(\alpha_{\mathrm{m}}\right)$.

4. Eksentrisitas

Eksentrisitas (e) adalah jarak antara resultan gaya dengan titik tengah struktur. Nilai e dihitung dengan membagi total momen dibagi dengan gaya vertikal. Nilai minimum e yang disyaratkan adalah 1/6 L.

Eksentrisitas e dapat diperoleh dari persamaan:

$$
e=\sum \frac{F 1 \cdot \frac{H}{2}+F 2 \cdot \frac{H}{3}-F 3 \cdot \frac{d}{3}}{\gamma \cdot H \cdot L+q \cdot L}<\frac{1}{6} L
$$

Dengan $\mathrm{q}=$ beban luar merata dan $\gamma=$ berat jenis tanah timbunan.

5. $\quad$ Daya dukung fondasi

Daya dukung dihitung berdasarkan distribusi Meyerhof dengan membagi daya dukung ultimit dengan beban dari struktur dinding MSE.

Faktor keamanan daya dukung fondasi FK dapat diperoleh dari persamaan:

$$
\mathrm{FK}=\frac{\left(\mathrm{c} . \mathrm{N}_{C}+0,5 \cdot \gamma \cdot L \cdot \mathrm{N}_{\gamma}\right)(L-2 e)}{R_{v}}
$$

Dengan $\mathrm{c}=$ kohesi tanah, $\gamma$ = berat jenis tanah dasar dan $\mathrm{N}_{\mathrm{c}}, \mathrm{N}_{\gamma}=$ faktor daya dukung.

Syarat fakktor keamanan sebagai berikut:

- Stabilitas geser, FK $>2$

- Stabilitas guling, FK > 1,5

- Stabilitas daya dukung tanah, FK $>3$ 
- Stabilitas global, FK > 1,5 atau FK > 1,3 jika parameter lengkap dan reliabel.

- Stabilitas terhadap gempa, FK $>1,1$

\section{Metode Elemen Hingga}

Metode elemen hingga pertama kali diperkenalkan pada dunia geoteknik oleh Clough dan Woodward pada tahun 1967. Metode ini memberikan potensi besar untuk mengatasi permasalahan geoteknik selama ini karena mampu memodelkan perilaku ketegangan nonlinear tanah. Beberapa model sederhana seperti linear model elastic, model elastic multilinear, model elastic hyperbolic atau model elastoplastic dapat digunakan untuk menyederhanakan hubungan tegangan-regangan dan mampu memberikan hasil yang baik. Dalam penggunaan model elastoplastis, karakteristik tanah model konstitutif, seperti elastisitas, fungsi yield, fungsi potensial serta harus dikalibrasi dengan tes laboratorium. (Syahwaner, Yusa, \& Satibi, 2019)

Model yang paling sederhana yang sering digunakan yaitu model elastis linier karena hanya membutuhkan dua parameter modulus young (E), dan poisson rasio (v). Namun, model ini kurang baik untuk digunakan dalam material tanah kecuali pada tekanan rendah dan tingkat ketegangan kecil sehingga dapat digunakan model elastik plastic dalam model tanah. Pemodelan Mohr-Coulomb adalah model yang paling sering digunakan dalam mekanika tanah. (Syahwaner, Yusa, \& Satibi, 2019)

Program berbasis elemen hingga adalah sebuah software yang dapat digunakan untuk menganalisis konsolidasi, deformasi, stabilitas dan aliran air tanah dalam geotechnical engineering. Cara kerja elemen hingga yaitu dengan memecah (mendiskritisasi) model dari objek dengan membagi objek kedalam elemen-elemen yang lebih kecil (finite element) yang terhubung oleh titik-titik (nodes) yang digunakan oleh elemen-elemen tersebut dan sebagai batas dari elemen hingga. (Stevens \& Tedianto, 2018) Elemen-elemen yang dipecah berupa elemen segitiga. Pada setiap elemen terdiri dari nodal dan titik tegangan. Proses pembagaian elemen ini biasanya disebut mesh. Semakin banyak elemen dalam analisis maka haqsilnya akan menjadi lebih teliti, tetapi waktu yang diperlukan untuk pehitungan menjadi lebih lama.

Dalam pemodelan Mohr-Coulomb dimana memerlukan parameter seperti berat jenis basah dan kering, modulus young (E), dan poisson rasio (v), kohesi (c), sudut geser ( $\phi$ ) dan sudut dilatasi ( $\varphi$ ). Pada model Mohr-Coulomb pola keruntuhan pada grafik tegangan-regangan berupa garis linear.

Untuk pemodelan levelling pad dan panel muka menggunakan elemen plate. Parameter yang diperlukan berupa berat jenis, tebal pelat, poisson rasio (v), kekakuan tarik/tekan (EA) dan kekakuan tekuk (EI). Pada pemodelan perkuatan digunakan elemen geogrid dengan parameter yng diperlukan seperti kekakuan tarik/tekan (EA). kekakuan tarik/tekan (EA) diperoleh dengan membagi kuat tarik nominal (kN/m) dengan elongasi (\%). Untuk dinding penahan tanah, elongasi ijinnya yaitu 1,5-2\%.

\section{METODE PENELITIAN}

\section{Metodologi penelitian}

Tahapan dari penelitian ini dapat dilihat pada Gambar 2.

1. Data perencanaan

Data awal yang dimiliki untuk perencanaan.

2. Studi literatur

Mengumpulkan teori-teori yang digunakan untuk melakukan analisis panjang penjangkaran pada back-to-back mechanically stabilized earth walls berupa buku-buku, jurnal, artikel dan tutorial.

3. Analisis data perencanaan

Mengkorelasikan data-data tanah yang ada dan menentukan parameter-parameter yang dibutuhkan perhitungan.

4. Hasil perhitungan

Hasil perhitungan dari penelitian ini adalah berupa perhitungan manual yang dilanjutkan dengan menggunakan program berbasis elemen hingga.

5. Analisis hasil

Melakukan analisis dengan mencari pengaruh panjang penjangkaran terhadap stabilitas struktur serta mencari perbandingan rasio panjang penjangkaran terhadap tinggi pada back-to-back mechanically stabilized earth walls. Selain itu, juga dianalisis pengaruh dari penggunaan material timbunan berupa tanah merah dan pasir.

\section{Pengumpulan data}


Pada analisis ini, data tanah yang akan dipakai pada analisis ini berupa data tanah pada proyek jalan di Sulawesi Selatan. Data tanah yang diperlukan berupa data bor yang berisi N-SPT, data laboratorium, dan boring log. Selain itu, data yang diperlukan berupa dimensi dari back-to-back mechanically stabilized earth walls.

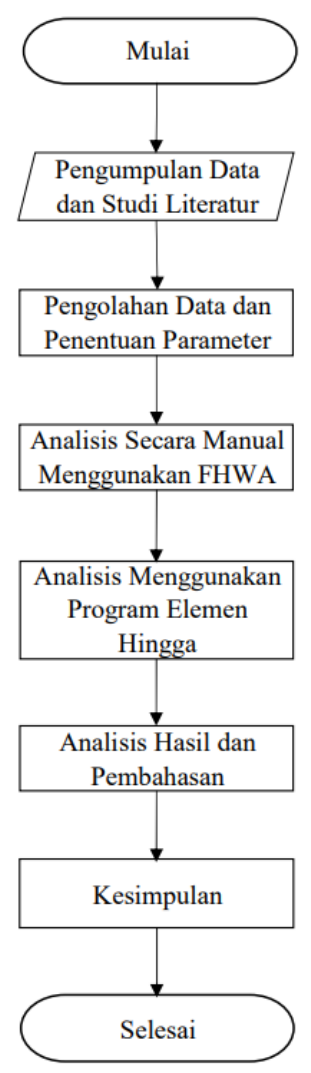

Gambar 2. Diagram alir penelitian

\section{HASIL DAN PEMBAHASAN}

Analisis terhadap stabilitas back-to-back mechanically stabilized earth walls pada proyek jalan layang di Sulawesi Selatan dilakukan untuk memperoleh panjang penjangkaran optimum dari perkuatan serta pengaruh dari penggunaan material timbunan berupa tanah merah dan pasir. Dalam analisis manual, terdapat tiga hal yang divariasikan, yaitu rasio panjang penjangkaran terhadap tinggi, spasi verikal geogrid, dan jenis tanah timbunan. Selain itu juga dilakukan analisis menggunakan program berbasis elemen hingga yang digunakan untuk menghitung stabilitas global, gaya tarik pada geogrid dan deformasi yang terjadai pada tanah serta panel. Untuk analisis program terdapat dua variasi, yaitu rasio panjang penjangkaran terhadap tinggi dan jenis timbunan. Dari hasil analisis manual dan program, data yang diperoleh berupa kebutuhan kuat tarik geogrid dan faktor keamanan kemdian dibandingkan. Dengan analisis ini, akan diketahui panjang penjangkaran minimum dan pengaruh penggunaan tanah merah dan pasir sebagai material timbunan.

Tabel 1 berisi summary parameter tanah yang diperoleh dari data lab dan korelasi serta parameter timbunan.

Tabel 1. Parameter tanah

\begin{tabular}{llccccc}
\hline \multicolumn{1}{c}{ Parameter } & Satuan & $\begin{array}{c}\text { Lapisan 1 } \\
(0-7 \mathrm{~m})\end{array}$ & $\begin{array}{c}\text { Lapisan 2 } \\
(7-10 \mathrm{~m})\end{array}$ & $\begin{array}{c}\text { Lapisan 3 } \\
(10-30 \mathrm{~m})\end{array}$ & $\begin{array}{c}\text { Tanah } \\
\text { merah }\end{array}$ & Pasir \\
\hline Jenis tanah & - & lempung & lanau & batu kapur & lempung & pasir \\
$\gamma$ wet & $\mathrm{kN} / \mathrm{m}^{3}$ & 18 & 18 & 25 & 17 & 20 \\
$\gamma$ dry & $\mathrm{kN} / \mathrm{m}^{3}$ & 16 & 16 & 25 & 15 & 20 \\
Young modulus $(\mathrm{E})$ & $\mathrm{Mpa}$ & 10 & 40 & 30000 & 10 & 50 \\
Poisson ratio $(\mathrm{v})$ & - & 0,33 & 0,33 & 0,3 & 0,33 & 0.3 \\
Kohesi $(\mathrm{c})$ & $\mathrm{kN} / \mathrm{m}^{2}$ & 20 & 30 & - & 25 & - \\
Sudut geser $(\phi)$ & $\circ$ & 7 & 30 & 40 & 20 & 35 \\
\hline
\end{tabular}


Gambar 3 berisi data perencanaan dari back-to-back mechanically stabilized earth walls.

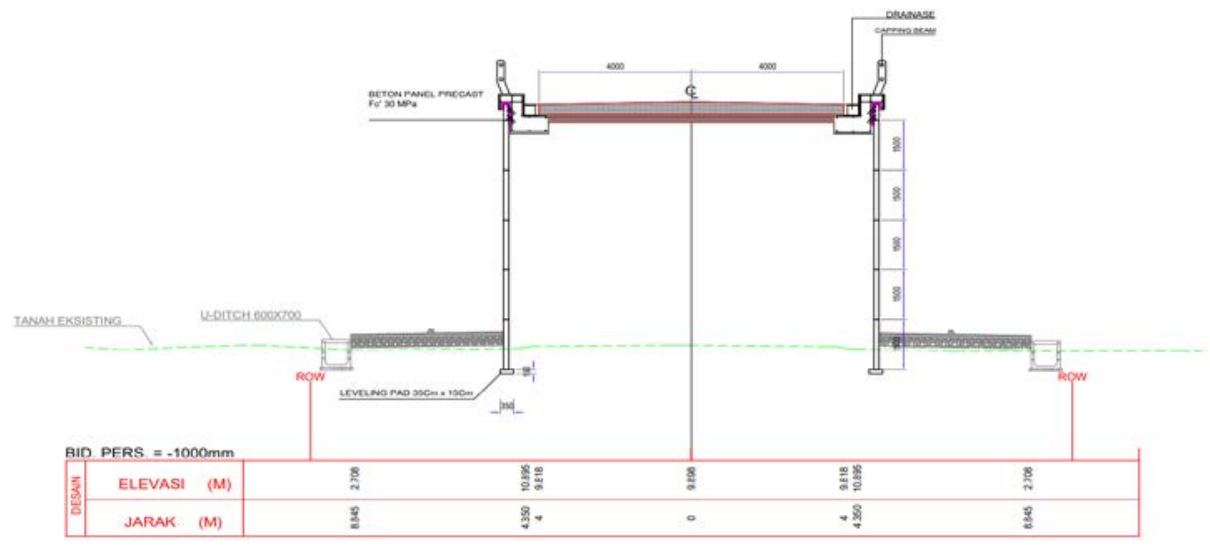

Gambar 3. Potongan Melintang MSE Walls

Tabel 2 berisi data material properties dari panel dan plate.

Tabel 2. Material properties panel dan plate

\begin{tabular}{llcc}
\hline \multicolumn{1}{c}{ Type } & Satuan & Levelling pad & Concrete panel \\
\hline Fc' & $\mathrm{MPa}$ & 30 & 30 \\
Young modulus (E) & $\mathrm{kN} / \mathrm{m}^{2}$ & $2,57 \times 10^{7}$ & $2,57 \times 10^{7}$ \\
Ketebalan (d) & $\mathrm{m}$ & 0,15 & 0,14 \\
Axial Stiffness (EA) & $\mathrm{kN} / \mathrm{m}$ & $3,86 \times 10^{6}$ & $3,6 \times 10^{6}$ \\
Bending stiffness (EI) & $\mathrm{kN} / \mathrm{m}^{2}$ & 7240 & 5880 \\
Berat (w) & $\mathrm{kN} / \mathrm{m}$ & 3,6 & 3,36 \\
Poisson ratio $(\mathrm{v})$ & - & 0,2 & 0,2 \\
\hline
\end{tabular}

Tabel 3 berisi data material properties dari geogrid PET dengan coating PVC

Tabel 3. Material properties geogrid

\begin{tabular}{lcc}
\hline \multicolumn{1}{c}{ Type } & Satuan & Geogrid \\
\hline Ultimate Tensile $\left(\mathrm{T}_{\mathrm{ult}}\right)$ & $\mathrm{kN} / \mathrm{m}$ & 200 \\
Reduced Tensile $\left(\mathrm{T}_{\text {all }}\right)$ & $\mathrm{kN} / \mathrm{m}$ & 70 \\
Axial Stiffness $\left(\mathrm{EA}_{1}\right)$ & $\mathrm{kN} / \mathrm{m}$ & 3497 \\
\hline
\end{tabular}

\section{Analisis manual stabilitas internal}

stabilitas internal back-to-back mechanically stabilized earth walls terdiri dari pullout resistance dan tensile failure. Pada studi kasus ini berupa dinding back-to-back dan perhitungan untuk masing-masing dinding dihitung tersendiri.

1. Tegangan lateral tanah

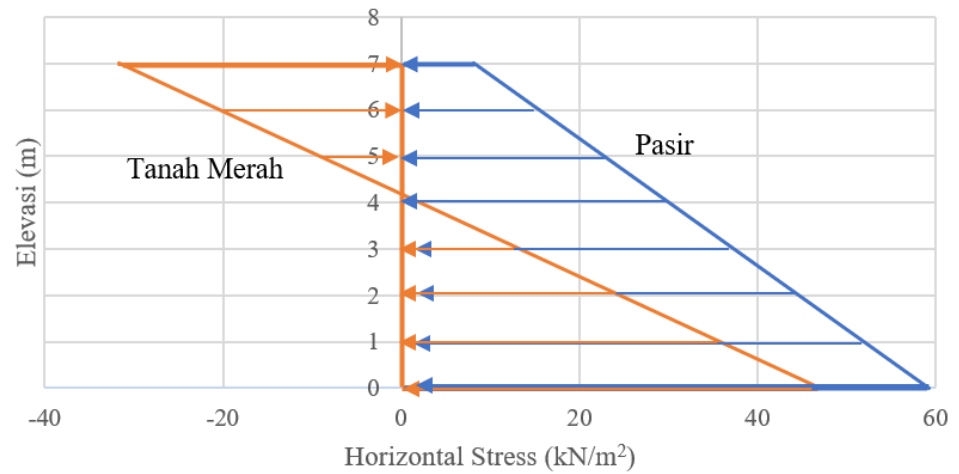

Gambar 4. Tegangan lateral 
Berdasarkan Gambar 4, dapat dilihat untuk ketinggian dinding $7 \mathrm{~m}$ tekanan lateral pada tanah merah bernilai negatif. Hal ini dikarenakan pada tanah merah terdapat kohesi yang mengurangi tegangan lateral dari berat sendiri tanah. Untuk pasir tidak memiliki kohesi sehingga tekanan lateralnya lebih besar yaitu 47,0556 kN/m² pada tanah merah dan $59,34 \mathrm{kN} / \mathrm{m}^{2}$ pada pasir.

2. Gaya tarik maksimum yang terjadi

Gaya tarik maksimum dihitung secara manual untuk tanah merah dan pasir. Pada perhitungan ini dilakukan variasi untuk spasi vertikal yaitu 0,5 m, 0,6 m, 0,7 m, dan 0,8 m. Berikut gaya tarik maksimum yang diperoleh

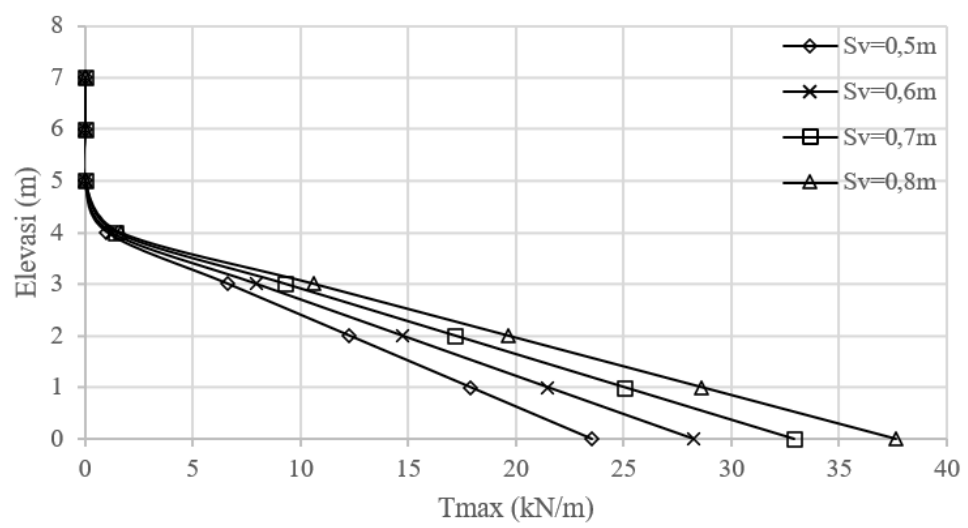

Gambar 5. Gaya tarik maksimum pada tanah merah

Pada Gambar 5 dapat dilihat untuk ketinggian dinding 4,5 m -7 m tidak ada gaya tarik pada geogrid karena tegangan lateral pada ketinggian tersebut bernilai negatif sehingga dapat dikatakan gaya tarik pada geogrid sama dengan nol. Gaya tarik maksimum terjadi pada dasar struktur dengan spasi vertikal 0,8 m yaitu 37,64 kN/m.

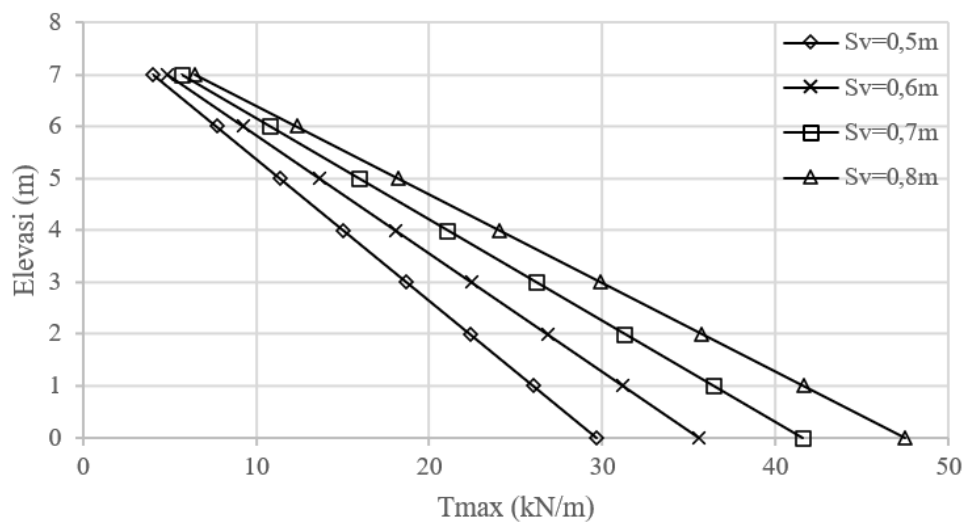

Gambar 6. Gaya tarik maksimum pada pasir

Pada Gambar 6 dapat dilihat, gaya tarik pada dasar struktur semakain besar karena tegangan lateralnya semakin besar. Pada grafik dilakukan variasi untuk spasis vertikal geogrid dan diperoleh, semakin besar spasinya maka gaya tariknya semakin besar. Untuk gaya tarik maksimum pasir lebih besar dari tanah merah karena pasir tidak memiliki kohesi. Gaya tarik maksimum terjadi pada dasar struktur dengan spasi vertikal 0,8 m yaitu 47,47 kN/m.

\section{Kapasitas tarik geogrid}

Digunakan geogrid dengan kapasitas tarik ultimit sebesar 200 kN. Kapasitas ini harus direduksi dengan faktor kerusakan instalasi, creep, dan reduksi kekuatan sehingga diperoleh kekuatan tarik ijin sebesar 62,94 kN/m.

\section{Kapasitas Cabut}

Perhitungan kapasitas cabut dari geogrid dilakukan variasi untuk rasio perbandingan panjnag penjangkaran dengan tinggi dinding, $\mathrm{L} / \mathrm{H}=0,6-0,7$. Dari tabel di bawah dapat dilihat kapasitas cabut untuk pasir lebih besar daripada tanah merah karena sudut geser pasir lebih besar. Berikut kapasitas cabut dari geogrid. 
Tabel 4. Kapasitas cabut geogrid

\begin{tabular}{ccccc}
\hline \multirow{2}{*}{ Jenis Timbunan } & \multirow{2}{*}{ Kondisi } & \multicolumn{3}{c}{$\mathrm{P}_{\mathrm{r}}(\mathrm{kN} / \mathrm{m})$} \\
\cline { 3 - 5 } & & $\mathrm{L}=0,6 \mathrm{H}$ & $\mathrm{L}=0,65 \mathrm{H}$ & $\mathrm{L}=0,7 \mathrm{H}$ \\
\hline \multirow{2}{*}{ Tanah Merah } & Statik & 100,24 & 116,94 & 133,65 \\
& Seismik & 106,92 & 124,74 & 142,56 \\
\multirow{2}{*}{ Pasir } & Statik & 226,87 & 264,68 & 302,49 \\
& Seismik & 241,99 & 282,32 & 322,66 \\
\hline
\end{tabular}

5. Kebutuhan kuat tarik geogrid

Kebutuhan kapasitas tarik dari geogrid dihitung merupakan kebutuhan total untuk kondisi statik dan seismik. Dalam perhitungan kebutuhan kuat tarik geogrid dilakukan variasi untuk spasi vertikal yaitu 0,5 m, 0,6 m, 0,7 m, dan 0,8 m. Berikut gaya tarik maksimum yang diperoleh.

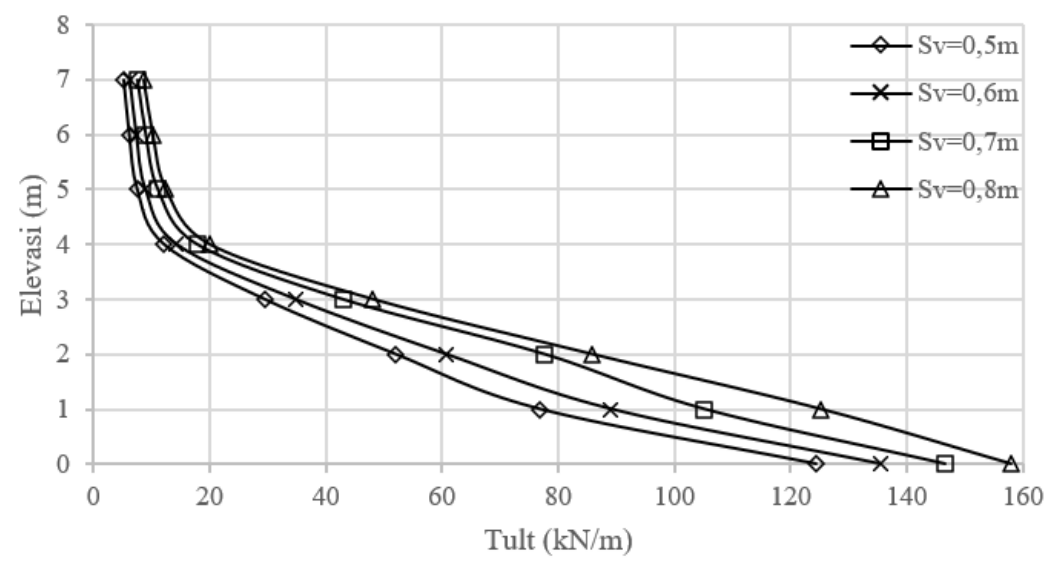

Gambar 7. Kebutuhan kapasitas tarik pada tanah merah

Pada Gambar 7 dapat dilihat kebutuhan kapasitas geogrid untuk tanah timbunan tanah merah semakin besar pada dasar struktur dan semakin besar jika spasi vertikal semakin besar. Untuk desain dipakai spasi vertikal 0,8 $\mathrm{m}$ sehingga kapasitas geogrid dibutuhkan sebesar 157,92 kN/m.

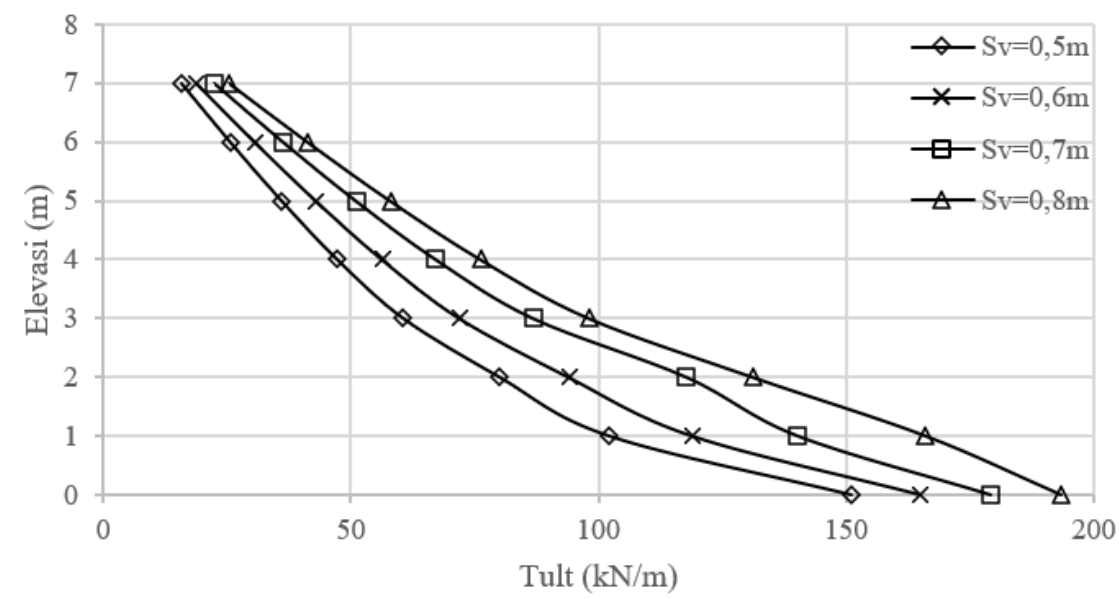

Gambar 8. Kebutuhan kapasitas tarik pada pasir

Pada Gambar 8 dapat dilihat kebutuhan kapasitas geogrid untuk tanah timbunan pasir lebih besar daripada tanah merah. Hal ini dikarenakan, untuk tanah merah tegangan lateral dikurangi dengan kohesi sedangkan pasir tidak memiliki kohesi. Untuk desain dipakai spasi vertikal sebesar 0,8 m sehingga kapasitas geogrid dibutuhkan sebesar $193,37 \mathrm{kN} / \mathrm{m}$. 


\section{Analisis manual stabilitas Eksternal}

Perhitungan stabilitas eksternal back-to-back mechanically stabilized earth walls terdiri dari stabilitas geser, stabilitas guling, dan daya dukung fondasi. Dalam stabilitas eksternal, terdapat dua kasus. Kasus pertama, dimana perkuatan tidak terjadi overlap dan kasus kedua terjadi overlap. Untuk penelitian ini terjadi overlapping perkuatan sehingga koefisien tekan aktif tanah harus direduksi. Apabila overlap lebih besar dari 0,3 tinggi dinding, maka koefisien tekan aktif tanah sama dengan nol.

1. Stabilitas geser statik

Dalam perhitungan stabilitas statik dilakukan variasi untuk rasio panjang penjangkaran terhadap tinggi dinding yaitu $\mathrm{L} / \mathrm{H}=0,6-0,7$ dan jenis material timbunan. Berikut faktor keamanan geser yang diperoleh.

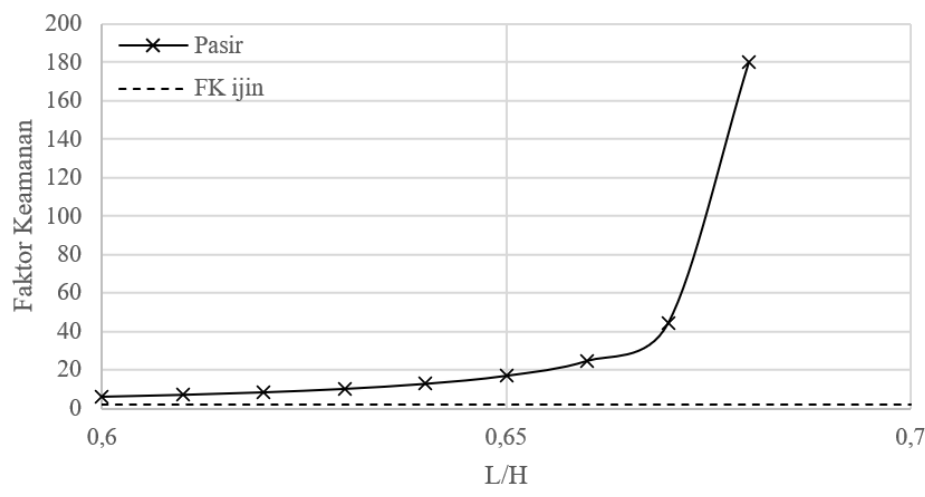

Gambar 9. Faktor keamanan geser pada kondisi statik

Pada Gambar 9 dapat dilihat bahwa faktor keamanan geser bertambah dengan bertambahnya L/H. Pada L/H > 0,68 faktor keamanan tidak diperhitungkan karena tekanan lateral tanah sama dengan nol. Faktor keamanan geser untuk tanah merah tidak diperhitungkan karena gaya pendorongnya bernilai negatif akibat kohesi. Faktor keamanan yang diperoleh telah melebihi faktor keamanan minimum.

2. Stabilitas guling statik

Dalam perhitungan stabilitas statik dilakukan variasi untuk rasio panjang penjangkaran terhadap tinggi dinding yaitu $\mathrm{L} / \mathrm{H}=0,6-0,7$ dan jenis material timbunan. Berikut faktor keamanan guling yang diperoleh.

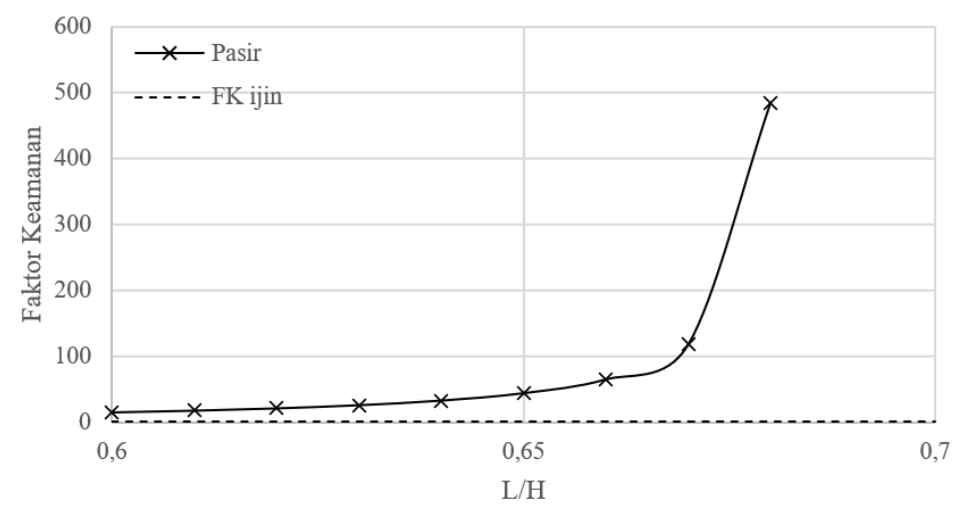

Gambar 10. Faktor keamanan guling pada kondisi statik

Pada Gambar 10 dapat dilihat bahwa faktor keamanan guling mirip dengan geser dimana akan bertambah jika L/H bertambah dan tidak perlu diperhitungkan jika $\mathrm{L} / \mathrm{H}>0$,68. Faktor guling untuk tanah merah tidak diperhitungkan karena gaya pendorongnya bernilai negatif akibat kohesi. Faktor keamanan yang diperoleh telah melebihi faktor keamanan minimum.

3. Stabilitas geser seismik

Perhitungan stabilitas seismik dilakukan dengan menambahkan gaya gempa sebagai gaya pendorong. Dalam perhitungannya dilakukan variasi untuk rasio panjang penjangkaran terhadap tinggi dinding yaitu $\mathrm{L} / \mathrm{H}=0,6-0,7 \mathrm{dan}$ jenis material timbunan. Berikut faktor keamanan geser seismik yang diperoleh. 


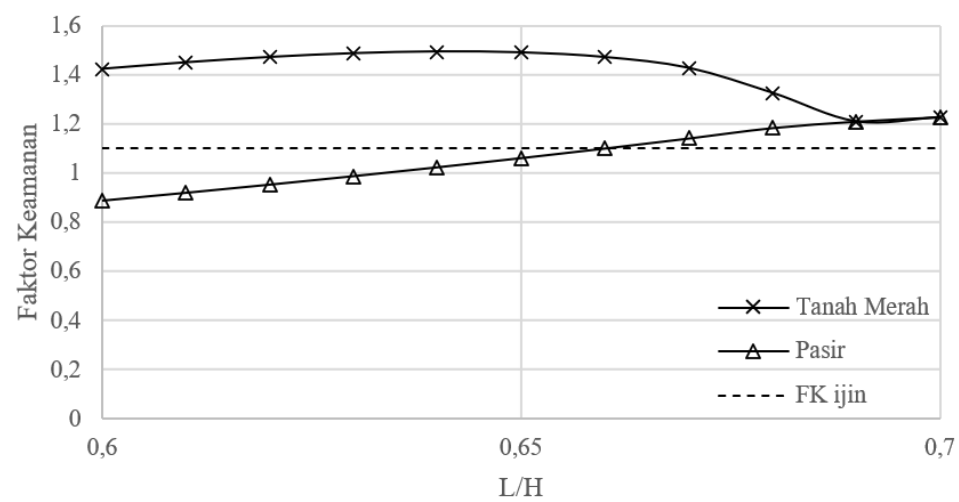

Gambar 11. Faktor keamanan geser pada kondisi seismik

Pada Gambar 11 dapat dilihat bahwa faktor keamanan geser seismik pada pasir berupa garis linier. Untuk $\mathrm{L} / \mathrm{H}<$ 0,66 faktor keamanan tidak memenuhi. Untuk tanaah merah dapat dilihat nilai FK dengan L/H 0,6-0,68 berbentuk parabola dan kemudian untuk L/H > 0,68 FK turun karena tidak ada tekanan tanah lateral.

4. Stabilitas guling seismik

Berikut faktor keamanan guling seismik yang diperoleh.

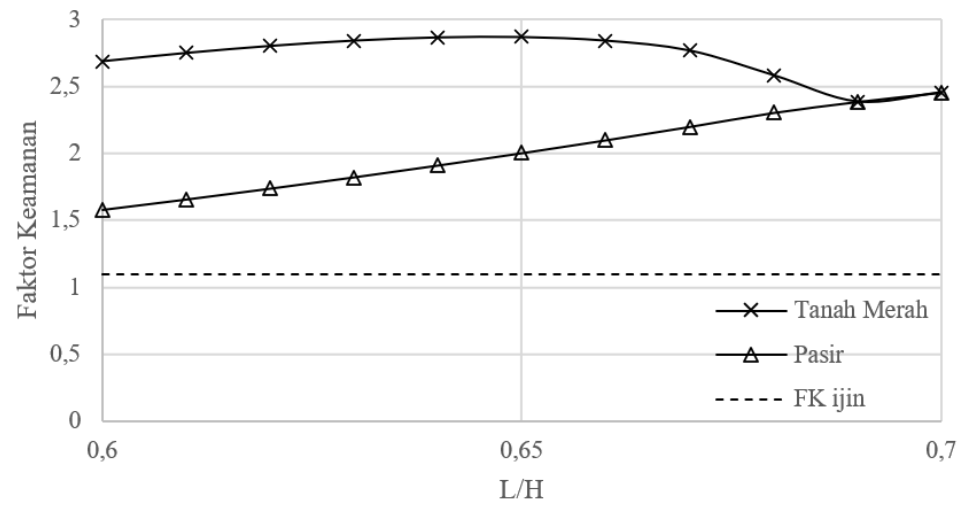

Gambar 12. Faktor keamanan guling pada kondisi seismik

Pada Gambar 12 dapat dilihat bahwa faktor keamanan guling seismik pada pasir berupa garis linier. Untuk tanaah merah dapat dilihat nilai FK untuk L/H 0,6-0,68 berbentuk parabola karena pengaruh dari kohesi dan kemudian untuk L/H > 0,68 FK turun karena tidak ada tekanan tanah lateral. Sebagai persyaratan stabilitas eksternal, apabila overlapping lebih besar dari 0,3 H maka koefisien aktif tanah sama dengan nol.

5. Daya dukung fondasi

Berikut faktor keamanan daya dukung fondasi yang diperoleh.

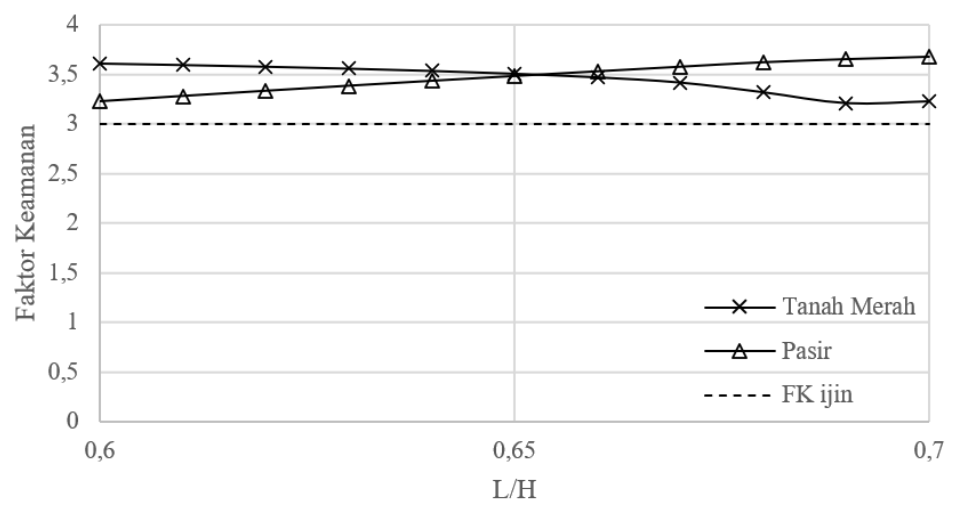

Gambar 13. Faktor keamanan daya dukung fondasi 
Pada Gambar 13 dapat dilihat bahwa faktor keamanan daya dukung pada pasir berupa garis linier. Untuk tanah merah dapat dilihat nilai FK untuk L/H 0,6-0,68 berbentuk parabola dan kemudian untuk L/H > 0,68 tidak ada tekanan lateral. Untuk daya dukung fondasi dilakukan perbaikan tanah dengan pemadatan tanah sedalam 3 meter. Untuk sudut geser awal tanah fondasi adalah $7^{\circ}$ dan dipadatkan menjadi $17^{\circ}$ untuk tanah merah dan $20^{\circ}$ untuk pasir.

\section{Analisis dengan program elemen hingga}

Perhitungan faktor keamanan menggunakan program berbasis elemen hingga. Pada metode ini, dimodelkan juga levelling pad dan facing panel dari back-to-back mechanically stabilized earth walls. Pada pemodelan ini dilakukan variasi panjang penjangkaran yaitu $\mathrm{L}=0,6 \mathrm{H}, \mathrm{L}=0,65 \mathrm{H}$, dan $\mathrm{L}=0,7 \mathrm{H}$. Untuk parameter tanah timbunan dilakukan variasi berupa tanah merah dan pasir untuk masing-masing panjang penjangkaran. Hasil analisis yang diperoleh sebagai berikut sebagai berikut:

Tabel 5. Faktor keamanan dan gaya tarik maksimum (FEM)

\begin{tabular}{ccccc}
\hline \multirow{2}{*}{$\mathrm{L} / \mathrm{H}$} & \multicolumn{2}{c}{ Faktor keamanan } & \multicolumn{2}{c}{$\mathrm{T}_{\max }(\mathrm{kN} / \mathrm{m})$} \\
\cline { 2 - 5 } & Tanah merah & Pasir & Tanah merah & Pasir \\
\hline 0,6 & 1,559 & 1,300 & 12,02 & 27,64 \\
0,65 & 1,555 & 1,298 & 12,09 & 27,29 \\
0,7 & 1,554 & 1,299 & 12,1 & 27,08 \\
\hline
\end{tabular}

Pemodelan pada program berbasis elemen hingga untuk tanah merah dengan $\mathrm{L}=0,6 \mathrm{H}$.
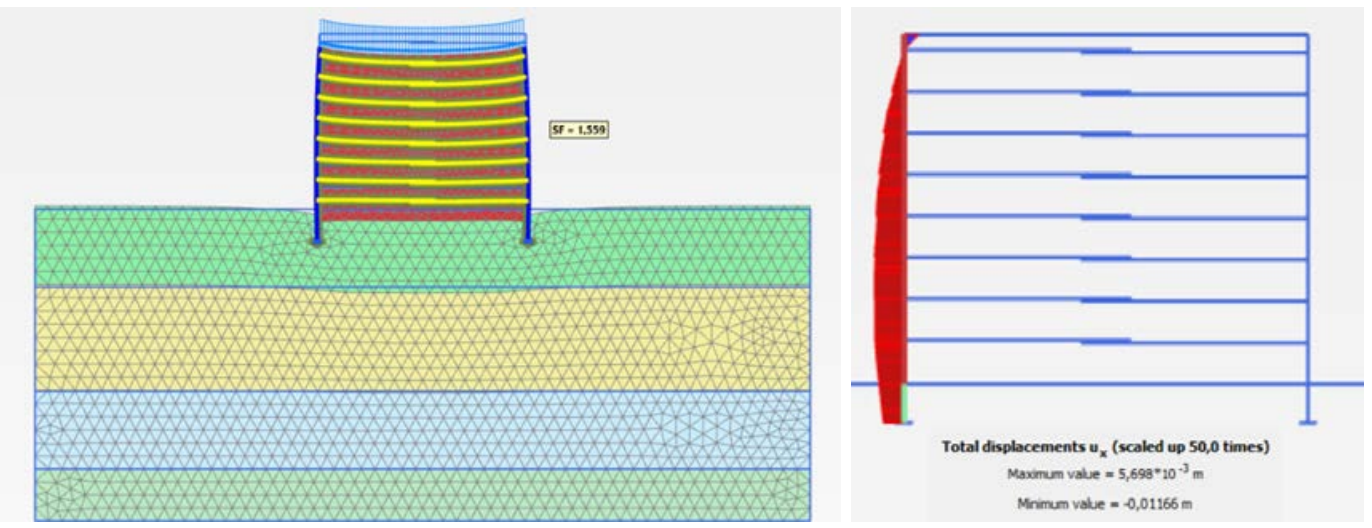

Gambar 14 Faktor keamanan stabilitas global dan deformasi pada panel

Berikut ini deformasi vertikal yang terjadi pada tanah dasar akibat struktur dinding MSE dan deformasi horizontal pada panel akibat tekanan lateral tanah timbunan.

Tabel 6. Faktor keamanan dan gaya tarik maksimum (LEM)

\begin{tabular}{ccccc}
\hline \multirow{2}{*}{$\mathbf{L} / \mathbf{H}$} & \multicolumn{2}{c}{ Deformasi vertikal (m) } & \multicolumn{2}{c}{ Deformasi horizontal (m) } \\
\cline { 2 - 5 } & Tanah merah & Pasir & Tanah merah & Pasir \\
\hline 0,6 & 0,01231 & 0,01772 & 0,01166 & 0,02384 \\
0,65 & 0,01231 & 0,01771 & 0,01145 & 0,02269 \\
0,7 & 0,01232 & 0,01771 & 0,01128 & 0,02188 \\
\hline
\end{tabular}

\section{KESIMPULAN DAN SARAN}

\section{Kesimpulan}

Berdasarkan analisis back-to-back mechanically stabilized earth walls pada jalan layang di Sulawesi Selatan, dapat diperoleh kesimpulan sebagai berikut:

1. Dari perhitungan stabilitas internal diperoleh gaya tarik maksimum dan kebutuhan kapasitas tarik geogrid pada tanah merah lebih kecil daripada pasir karena nilai kohesi juga ikut memberikan kontribusi terhadap pengurangan gaya lateral yang terjadi. Kebutuhan kapasitas tarik geogrid untuk spasi vertikal 0,8 m pada tanah merah yaitu 157,92 kN/m dan pasir yaitu 193,37 kN/m. 
2. Nilai rasio penjangkaran $(\mathrm{L} / \mathrm{H})$ minimum untuk pasir yaitu 0,66 dan tanah merah 0,6 . Faktor keamanan pada $\mathrm{L} / \mathrm{H}=0,66$ untuk pasir sebesar 1,10 dan pada $\mathrm{L} / \mathrm{H}=0,6$ untuk tanah merah sebesar 1,42.

3. Faktor keamanan untuk stabilitas geser pada tanah merah lebih besar daripada pasir. Stabilitas geser pada kondisi seismik untuk tanah merah yaitu 1,42 dan untuk pasir yaitu 0,89.

4. Faktor keamanan untuk stabilitas guling pada tanah merah lebih besar daripada pasir. Stabilitas guling pada kondisi seismik untuk tanah merah yaitu 2,69 dan untuk pasir yaitu 1,58.

5. Deformasi vertikal dan horizontal maksimum untuk material timbunan tanah merah lebih kecil dari pada pasir. Deformasi vertikal pada tanah merah yaitu 0,01232 m dan pada pasir yaitu 0,01771 m, sedangkan deformasi vertikal pada tanah merah yaitu 0,01128 $\mathrm{m}$ dan pada pasir yaitu 0,02188 $\mathrm{m}$.

6. Karena tanah dasar tidak memenuhi syarat minimum faktor keamanan fondasi yaitu 3 maka tanah dasar dipadatkan setebal $3 \mathrm{~m}$. Faktor keamanan sebelum dipadatkan untuk tanah merah sebesar 1,61 dan untuk pasir sebesar 1,08, sedangkan setelah dipadatkan faktor keamanan pada tanah merah menjadi 3,61 dan pada pasir menjadi 3,22.

\section{Saran}

Dari hasil penelitian ini, terdapat beberapa saran untuk melengkapi kekurangan dari penelitian ini, yaitu:

1. Jenis tanah timbunan dapat divariasikan untuk memperoleh sudut geser yang berbeda, misalnya $\phi=20^{\circ}$, $25^{\circ}$, dan $30^{\circ}$ sehingga dapat dilihat pengaruhnya terhadap stabilitas keseluruhan struktur.

2. Jenis perkuatan yang digunakan dapat diganti dengan jenis lain seperti besi strip, geotekstil atau geogrid tipe lainnya agar diperoleh pengaruhnya terhadap stabilitas struktur.

3. Pada penelitian ini, pengaruh gempa hanya diperhitungkan pada perhitungan manual untuk stabilitas internal dan eksternal maka untuk lebih baiknya pengaruh gempa dapat diperhitungkan pada analisis program.

4. Drainase pada tanah merah harus didesain dengan tepat agar air tidak masuk ke dalam struktur karena dapat menambah tekanan lateral dan mengurangi kapasitas cabut.

\section{DAFTAR PUSTAKA}

Badan Standarisasi Nasional. (2017). SNI 8460:2017 Persyaratan Perancangan Geoteknik. Jakarta.

Badan Standarisasi Nasional. (2019). SNI 1726:2019 Tata cara perencanaan ketahanan gempa untuk struktur bangunan gedung dan nongedung. Jakarta.

Eberhardt, E. (2018). Rock Engineering Practice and Design. UBC Geological Engineering.

FHWA. (2009). Design and Construction of Mechanically Stabilized Earth Walls and Reinforced Soil Slopes.

Khuzaifah, E. (2019). Studi tentang Dinding Penahan.

Pangestu, I. J., \& Suhendra, A. (2019). Analisis PerbandIngan Efek Gaya Gempa pada Dinding Penahan Tanah Gravitasi dengan Dinding Penahan Tanah Geosintetik. Jurnal Mitra Teknik Sipil.

Ratag, C. M., Mandagi, A. T., \& Legrans, R. R. (2018). Analisis Dinding Mechanically Stabilized Earth (MSE) (Studi Kasus : Ruas Jalan Tol Manado Bitung STA 6+45). Jurnal Sipil Statik Vol.6 No.8 Agustus 2018 (527540) ISSN: 2337-6732.

Simatupang, A., \& Iskandar, R. (2012). Perbandingan Antara Metode Limit Equilibrium Dan Metode Finite Element Dalam Analisis Stabilitas Lereng. Jurnal USU.

Stevens, D., \& Tedianto, L. S. (2018). Analisis Pengaruh Panjang Elemen Terhadap Kuat Tekan Dari Baja Ringan Profil Kanal dengan Metode Elemen Hingga. Jurnal Mitra Teknik Sipil Vol. 1, No. 1,.

Syahwaner, Y., Yusa, M., \& Satibi, S. (2019). Analisis Stabilitas Lereng dengan Perkuatan Tiang Menggunakan Metode Elemen Hingga (Studi Kasus Jalan Diponegoro Km. 2 Pasir Pengaraian). Jurnal APTEK Vol. 11 No.1. 